\title{
Effect of zeolitic hydroxyl nests on the acidity and propane aromatization performance of zinc nitrate impregnation modified HZSM-5 zeolite
}

Long Lin, Jiaxu Liu, Xiaotong Zhang, Jilei Wang, Chunyan Liu, Guang Xiong and Hongchen Guo*

State Key Laboratory of Fine Chemicals and School of Chemical Engineering, Dalian University of Technology, No. 2 Linggong Road, Dalian 116024

\section{Corresponding Author}

E-mail: hongchenguo@,dlut.edu.cn
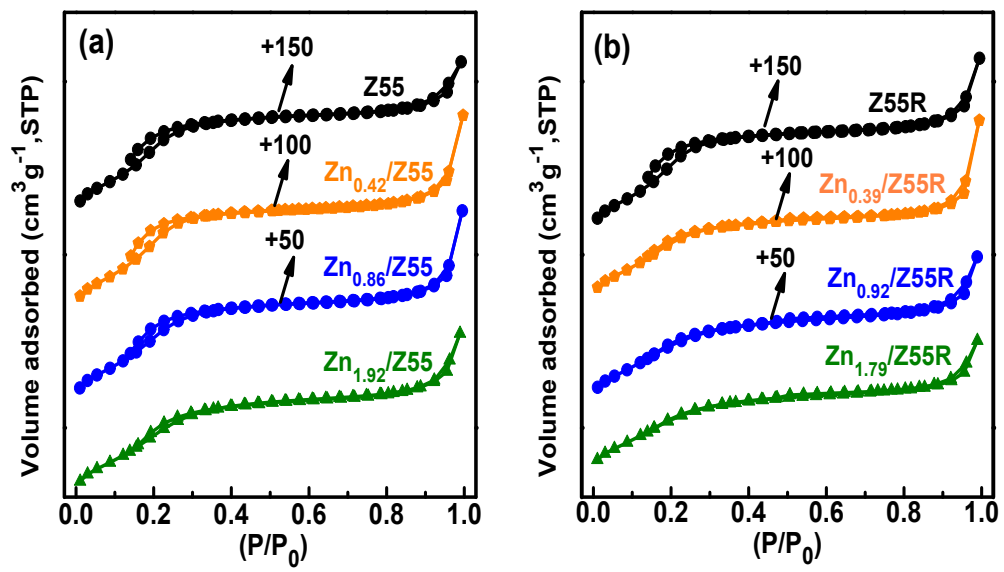

Fig S1. $\quad \mathrm{N}_{2}$ sorption isotherms of defective HZSM-5 zeolite (Z55), its "perfect" counterpart (Z55R) with low density of hydroxyl nests obtained by $\left(\mathrm{NH}_{4}\right)_{2} \mathrm{SiF}_{6}$ modification, and the zinc nitrate impregnation modified catalysts of them 


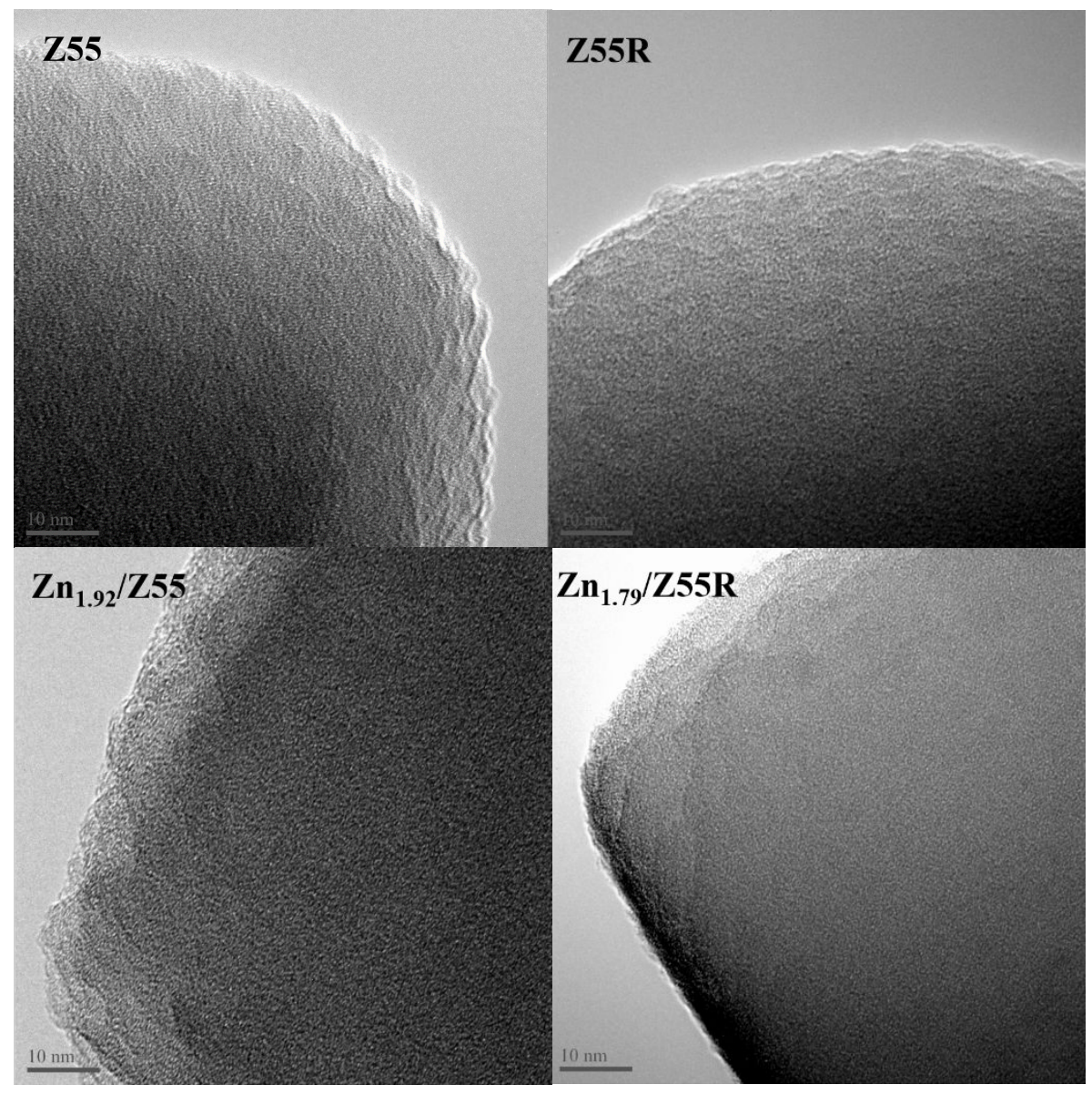

Fig S2. TEM of defective HZSM-5 zeolite (Z55), its "perfect" counterpart (Z55R) with low density of hydroxyl nests, and the zinc nitrate impregnation modified catalysts of them 

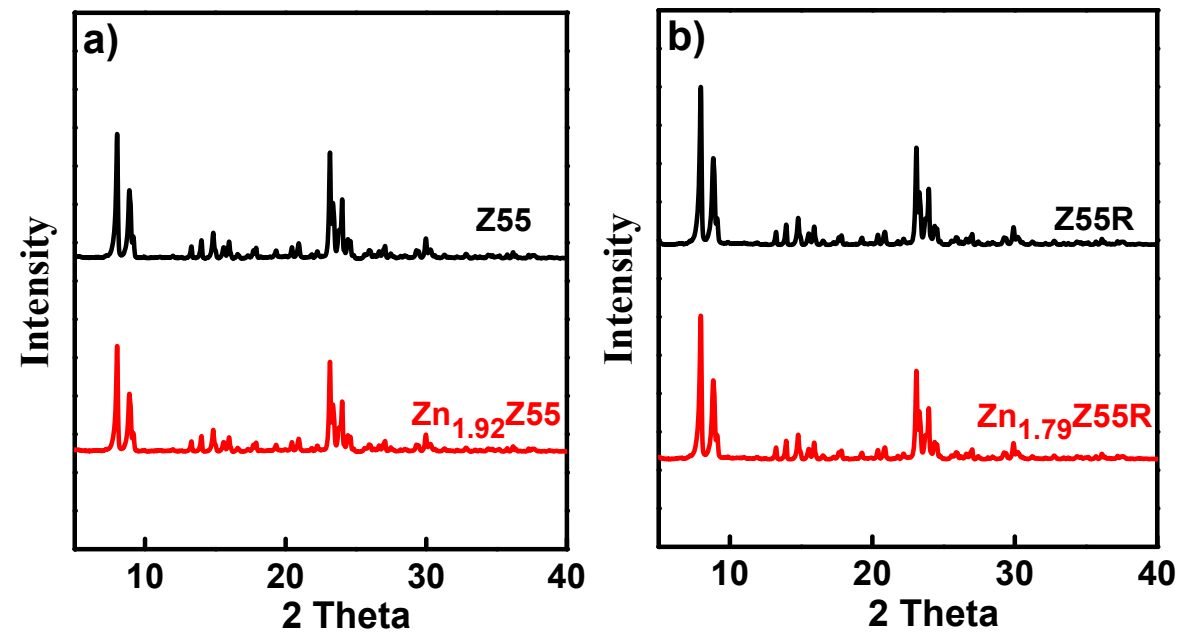

Fig S3. XRD of defective HZSM-5 zeolite (Z55), its "perfect" counterpart (Z55R) with low density of hydroxyl nests, and the zinc nitrate impregnation modified catalysts of them 